\title{
التصوير الجدارى فى ضوء الاستراتيجية القوهية وتأصيل الهوية المصرية
}

\author{
أ.م.د/ أسامة السيد السيد العاصي \\ أستاذ مساعد الرسم والتصوير - بقسم التربية الفنية بكلية التربية النوعية جامعه بورسعيد المبديد
}

\section{المقدمة}

يعد التصوير الجدارى من أخطر وأكثر المؤثرات الفنية على الاطلاق لأنه له احتكاك

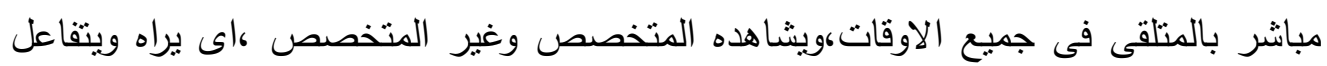

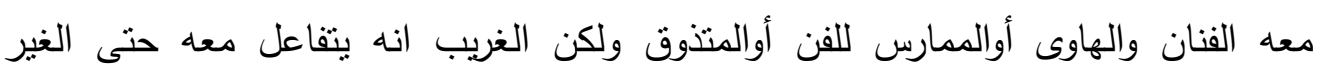

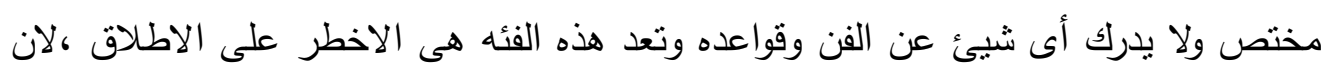

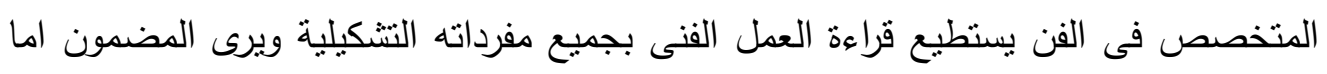
الغير متخصص فلا يرى الدرك الذى كونته ثقافته الذهنية والبصرية بصورة غير مباثرة عن الكن هذا العمل .

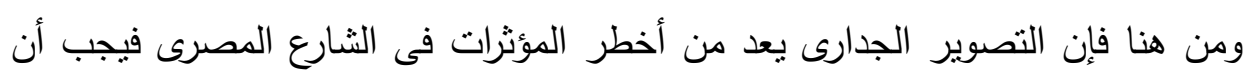

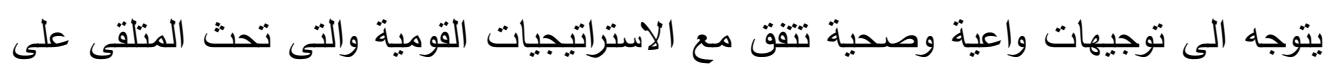
هدف صحيح ومعين كالعمل مثلا. وفى ضوء العولمة ، والمؤثرات الخارجية والثبكات العنكبوتية الضخمة والثقافات

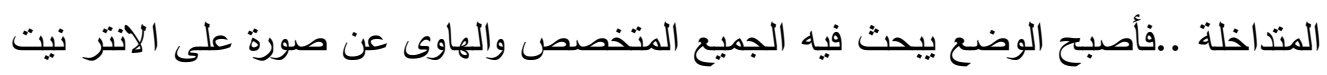

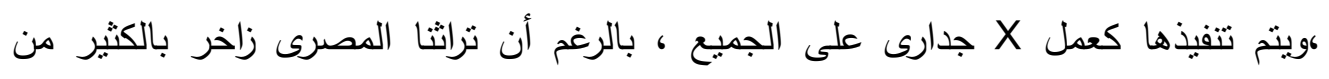

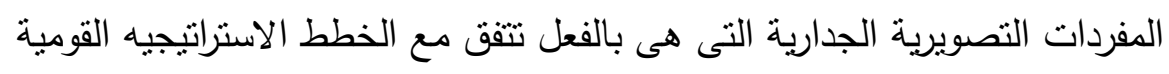

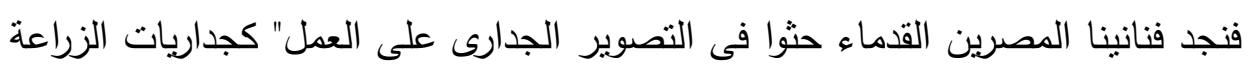

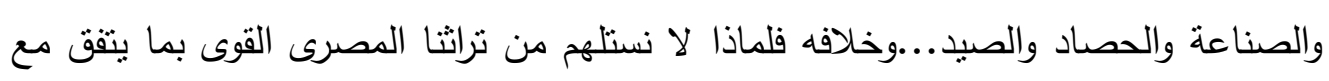
الاستراتيجيات القومية بدلا من البحث في محركات البحث "الانترنت وخلافه وكلا له ثقافتنة

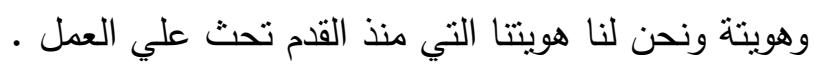

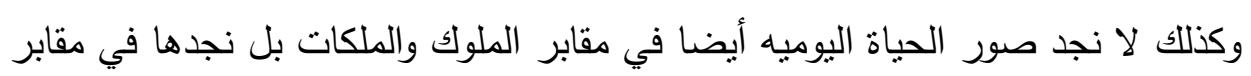

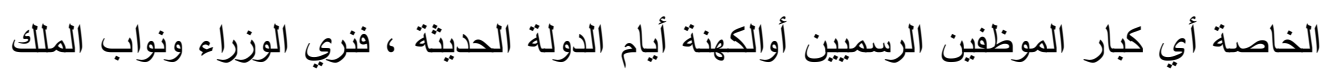


والقضاة ورؤساء الخدم وقاده الجند والكتبة والمشرفين علي الأملاك والمصانع والمصرين

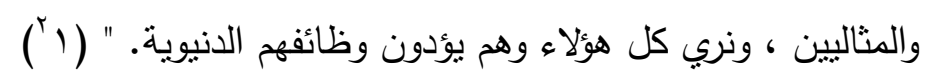

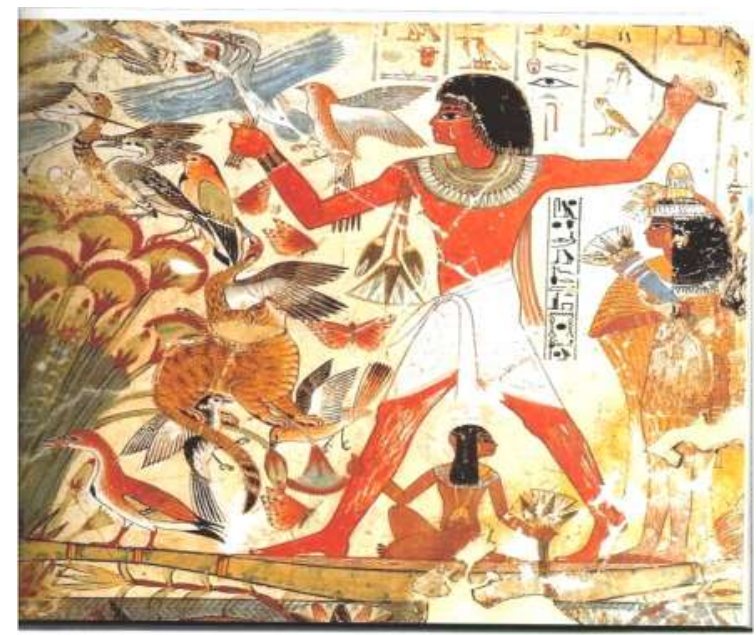

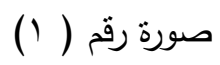

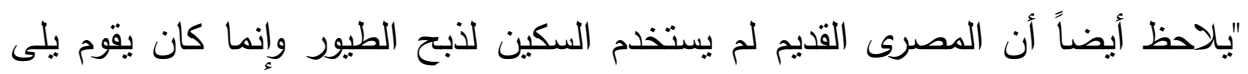
( يلوى ) عنق الطائر حتى يذهب عنه الحياة ، ثم يقوم بعد ذلك بشويه أو تقطيعه.

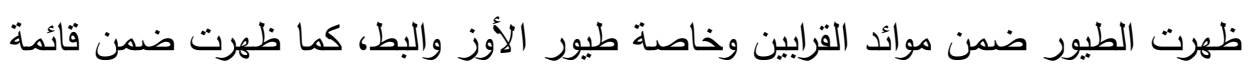

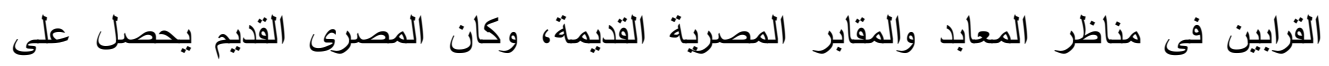

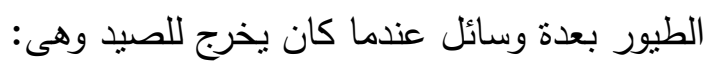
1- صبد الطيور بالثباك الكبيرة. r- صيد الطيور بعصى البوميرانج ( عصى الرماية ).

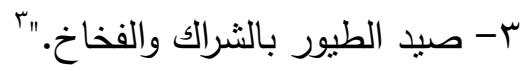

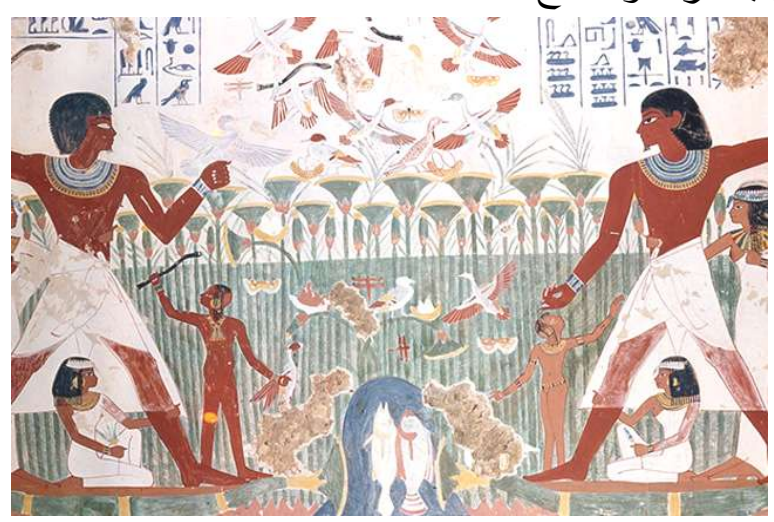

صورة (r) احد مشاهد الصيد ؟ 


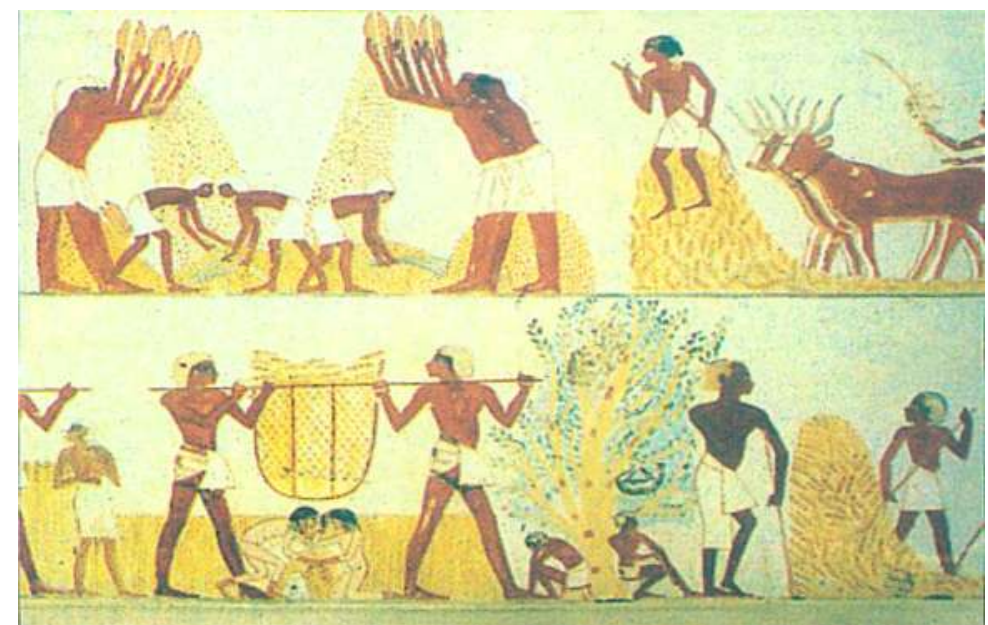

صورة رقم (r) - صل

$$
\text { "كتب : أبانوب وجيه }
$$

الثهور القبطية هي شهور مصرية قديمة مرتبطة بنجم الثعر اليماني Sirius ، والتي

استخدمها المصري القديم في كل ما يختص بالزراعة والحصاد ، ولا تزال هذه الثهور تستخدم في الريف المصري المعاصر ، حيث ان هذه الثهور كانت مرتبطة بمواعيد الزراعة والحصاد

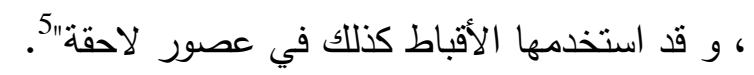

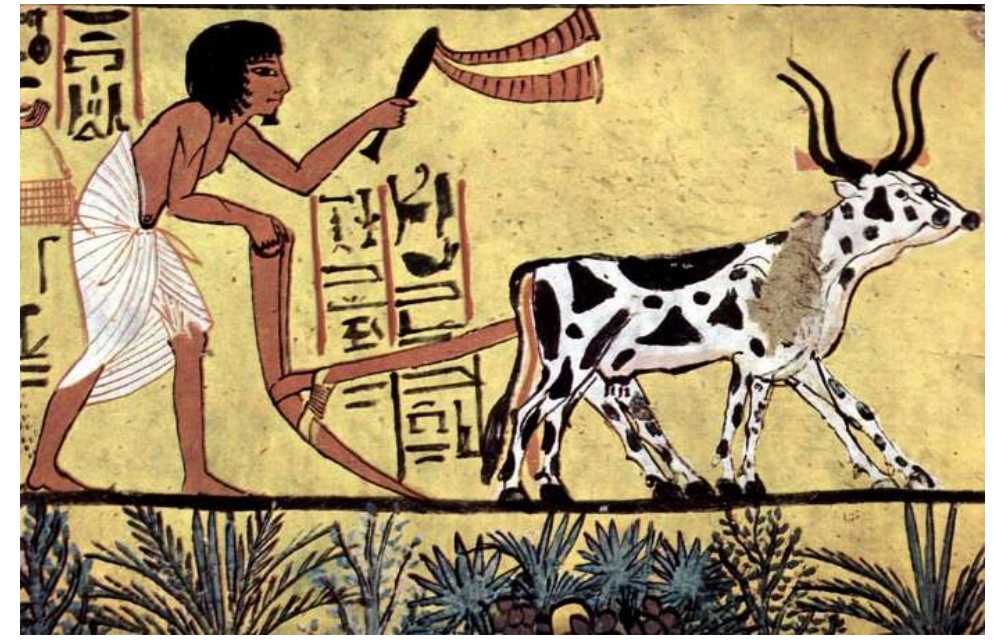

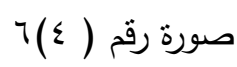



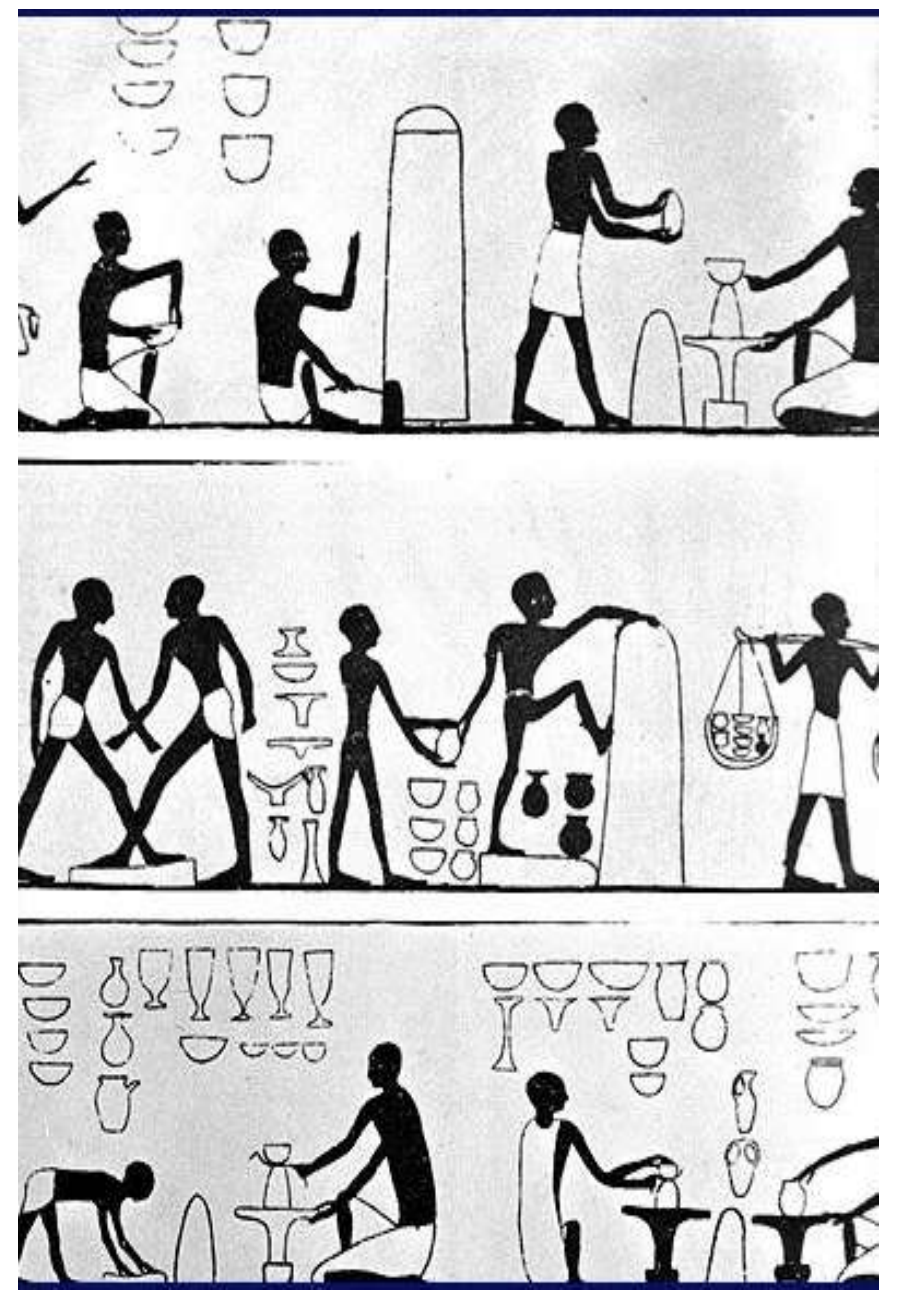

صورة رقم (0)

"الخزافون المصريون القدماء المصورون في لوحة الحائط، كما شكلوا، وشكلوا، وأطلقوا

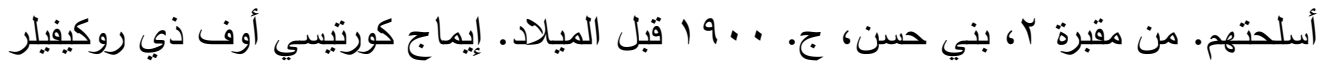
أرشايولوجيكال مسيوم

قام الخزافون المصريون القديمون بتصنيع بعض الأواني الفخارية والسيراميك الرائعة.

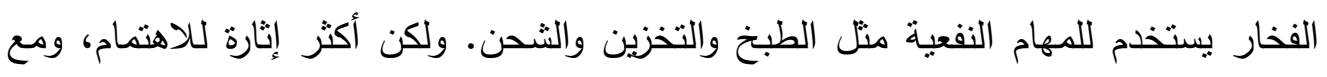

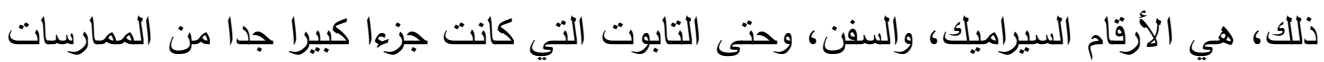

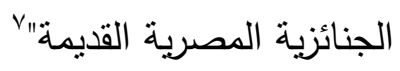
كما يوجد العديد من الفنانين المصريين المعاصريين الذين استلهموا من الفن المصري القديم . 


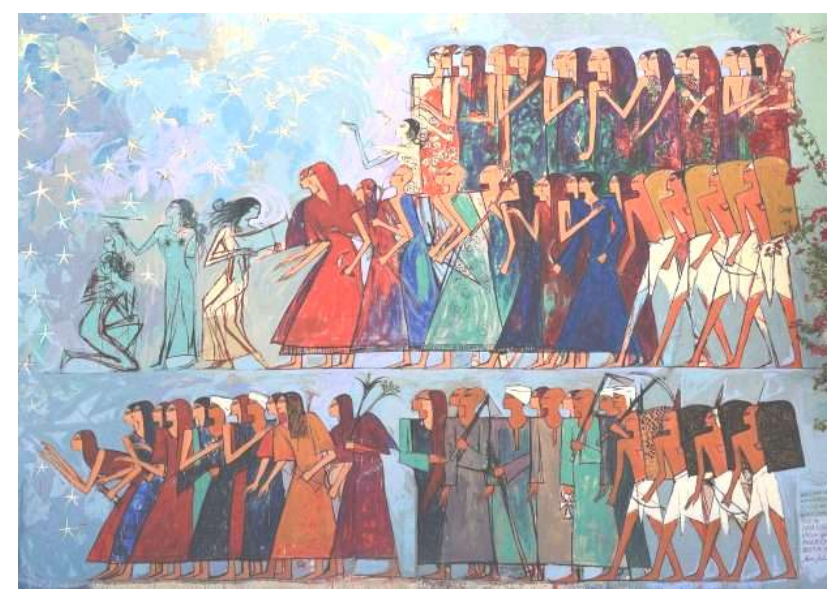

الصورة رقم (7) اعمال فنية للفنان علاء صبري

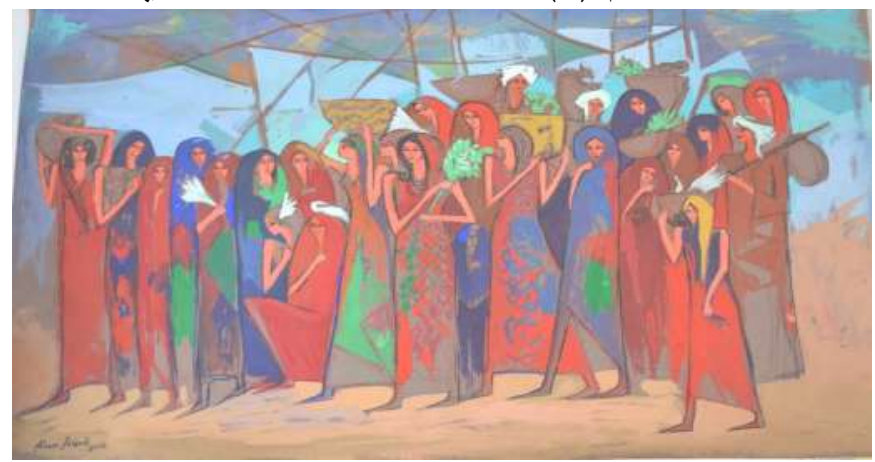

صورة رقم (V) اعمال فنية للفنان علاء صبري

يعد ( علاء صبري *) "فنان يعرف كيف يستقبد من تراثه التقافي والفني المتعدد والمتنوع

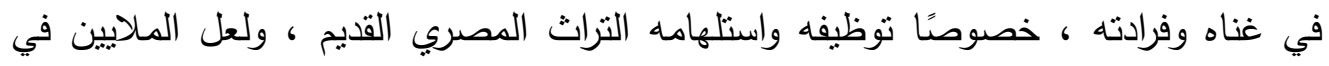

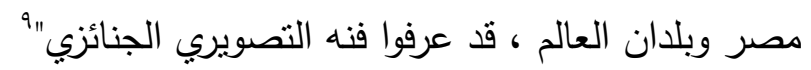

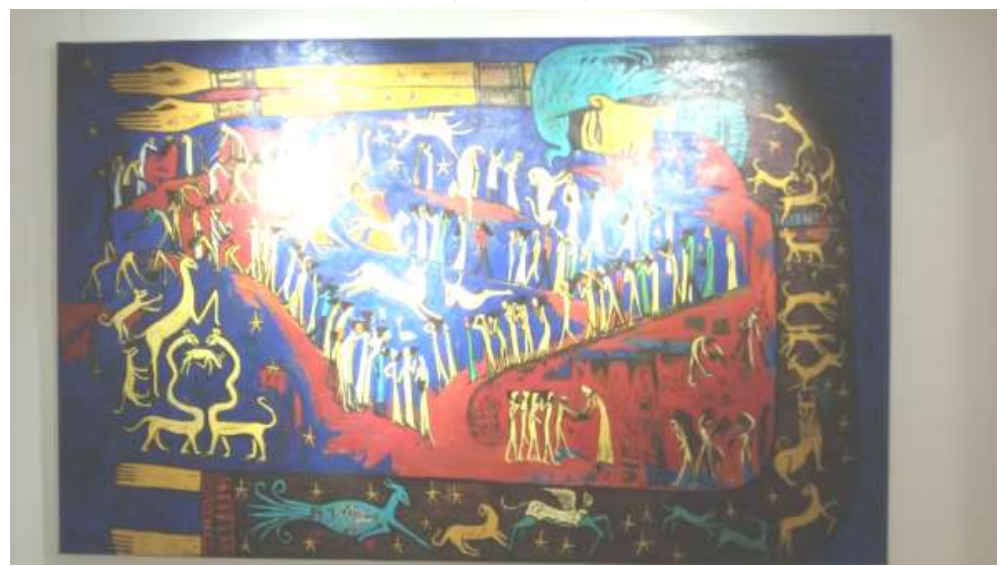

صورة رقم (^) اعمال فنية للفنان علاء صبري 


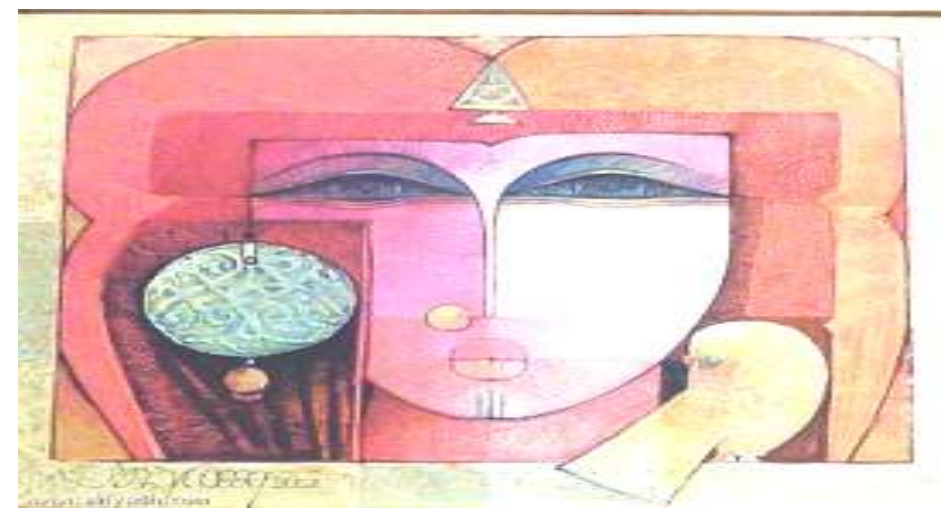

صورة رقم (^) الوحة فنية للفنان حبيب جورجي

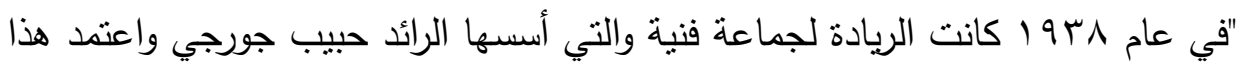

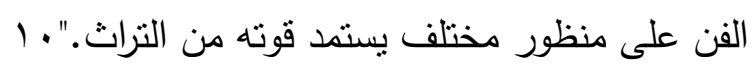

فنجد ان التراث المصري زاخر بالقيم التتكيلية والتعبيرية التي يمكن ان يستلاهم منها

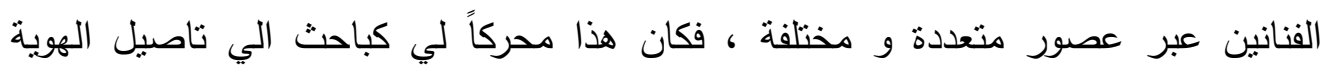

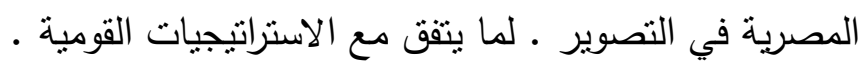
مشكلة البحث: تاتي مشكلة البحث في التساؤل الاتي - - س- هل بمكن الاستفادة من التصوير الجداري ذات الهوية المصرية في تتمية و وعي

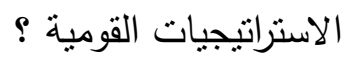
- - - هل يمكن التاكيد علي الاستراتيجيات القومية من خلا التصوير الجداري ذات

$$
\begin{aligned}
& \text { الهوية المصرية؟ } \\
& \text { أهداف البحث : }
\end{aligned}
$$

1-إستهدف البحث المحاولة من الافادة من التصوير الجداري ذات الهوية المصرية في تتمية

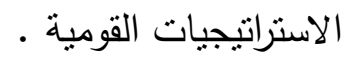

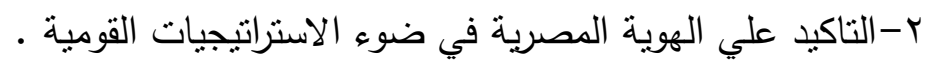
ب-ان يكون للتصوير الجداري هدف يتفق مع الاستراتيجيات القومية فروض البحث

ا-يمكن ان يكون هناك علاقة إيجابية بين التصوير الجداري ذات الهوية المصرية

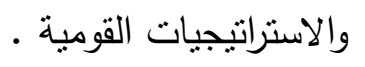

ץ-قد يكون للهوية المصرية دورا فعال في تتمية الاستراتيجيات القومية من خلال

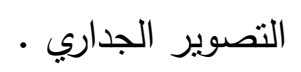


ا-بهتم البحث بدور التصوير الجداري ذات الهوية المصرية في تتمية ودعم الاستراتيجيات القومية .

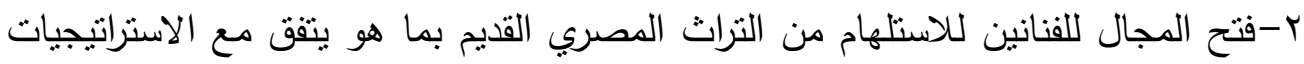

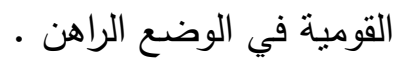

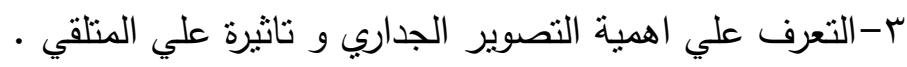
ع--إلقاء الضوء علي المواضيع في تراثتا المصري القديم التي تتفق مع الاستراتيجيات القومية

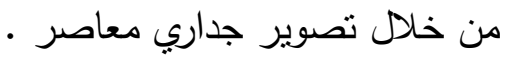

$$
\begin{aligned}
& \text { حدود البحث : } \\
& \text { تقتصر الدراسة علي الاتي : }
\end{aligned}
$$

ا-دراسة التصوير الجداري الحالي و كيفية الاستفادة منة في تتمية الاستراتيجيات القومية . r-توضيح المواضيع من تراثنا المصري القديم التي تحث و تتقق مع الاستراتيجيات القومية .

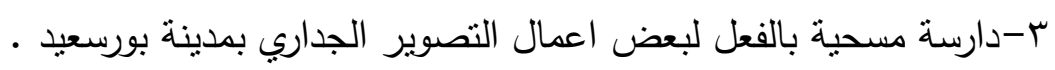

\section{منهج البحث :}

يتبع هذا البحث كلا من المنهجين الوصفي من حيث الاطار النظري والمنهج التحليلي

$$
\text { من حيث الاطار العملي }
$$

ا-دراسة نظرية عن التصوير الجداري في ضوء الاستراتيجيات القومية و دورة في التاكيد

$$
\begin{aligned}
& \text { علي الهوية المصرية . } \\
& \text { ثانيا: الاطار العمليـ }
\end{aligned}
$$

تحليل لبعض الاعمال الميدانية بالفعل في مدينة بورسعيد .

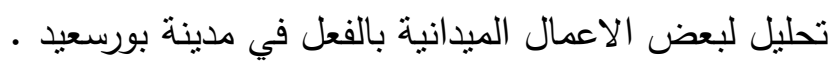

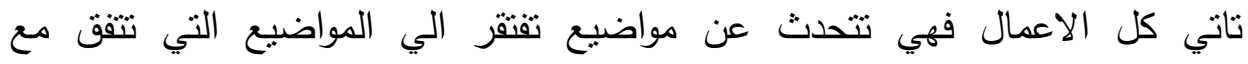
الاستراتيجيات القومية .كما ان البناء العام لها غير منقن وغير متفق دمع معاير القيم التعبيرية والتشكيلية المتعارف عليها. كما الالوان غير متتاسقة ، وترتيباب الموضوعات غير منوافق مع بعضها لبعض وفيما يلي علاض لبعض نماذج تمل اللوحات . 


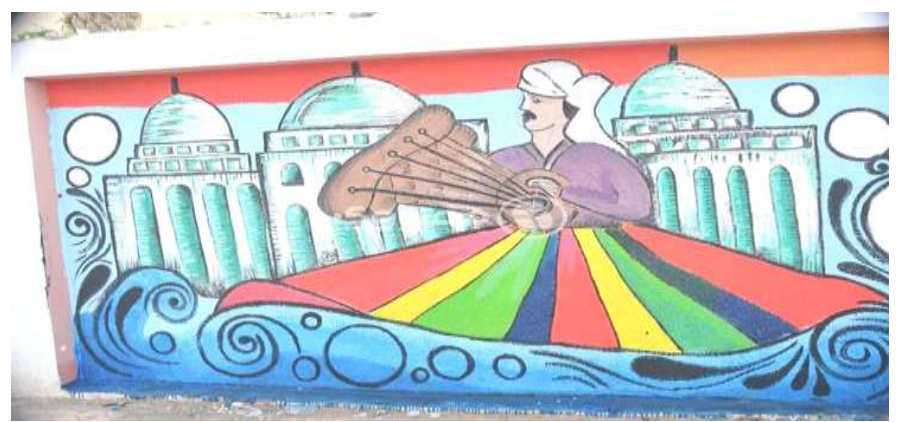

صورة رقم (9)

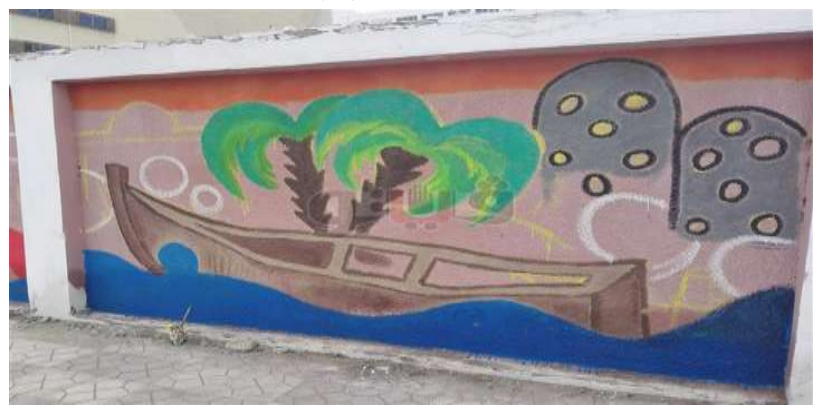

صورة رقم (·)

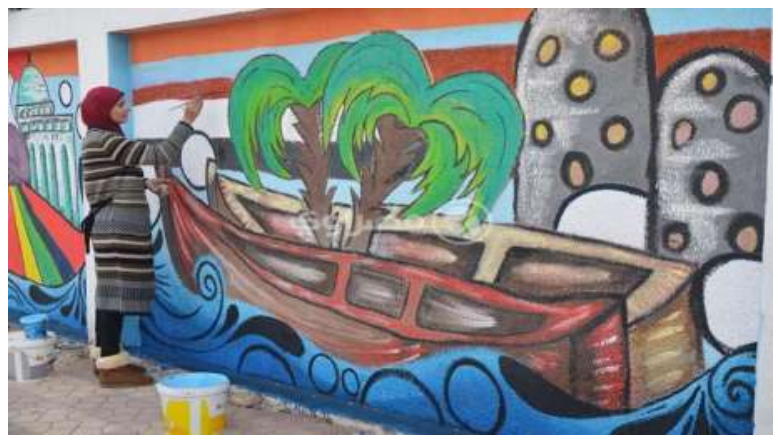

صورة رقم (1)

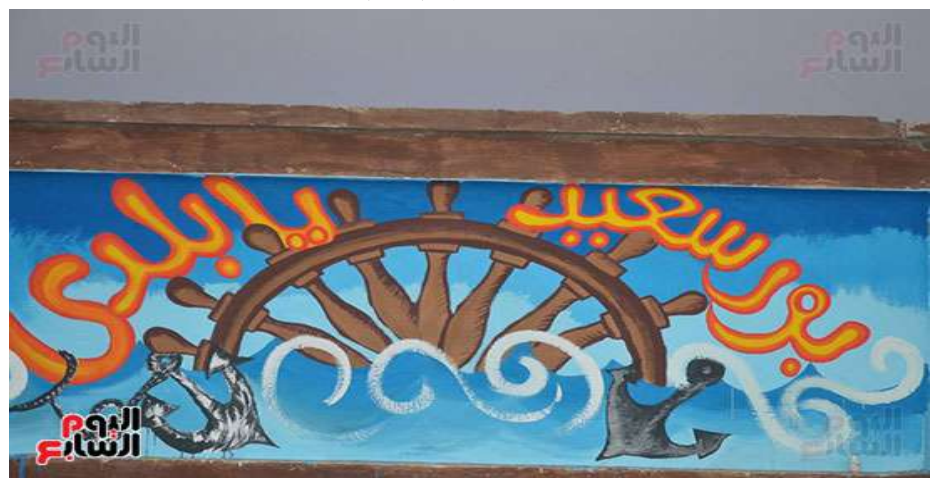

صورة رقم (r) 


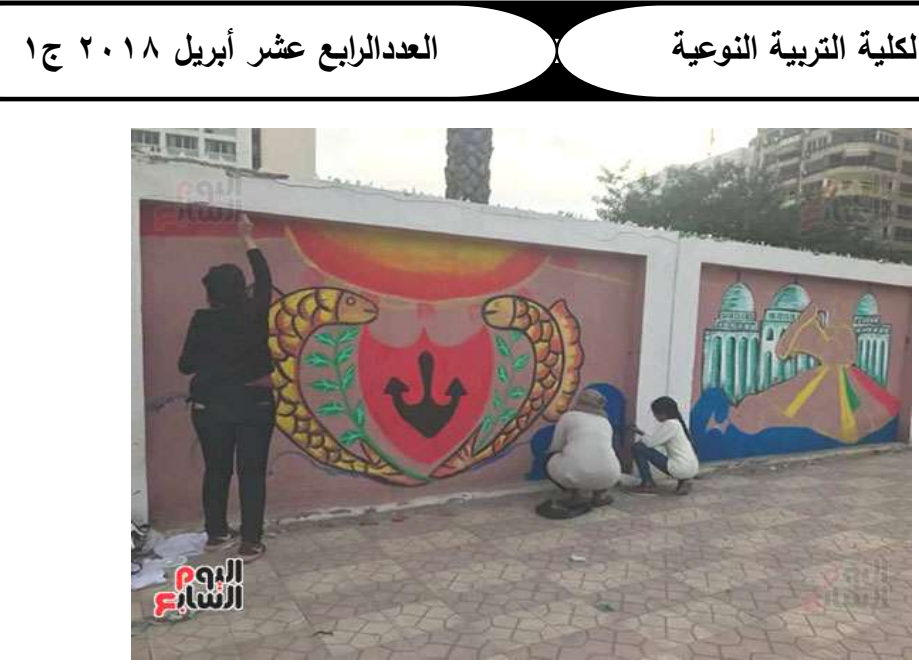

صورة رقم (TI)

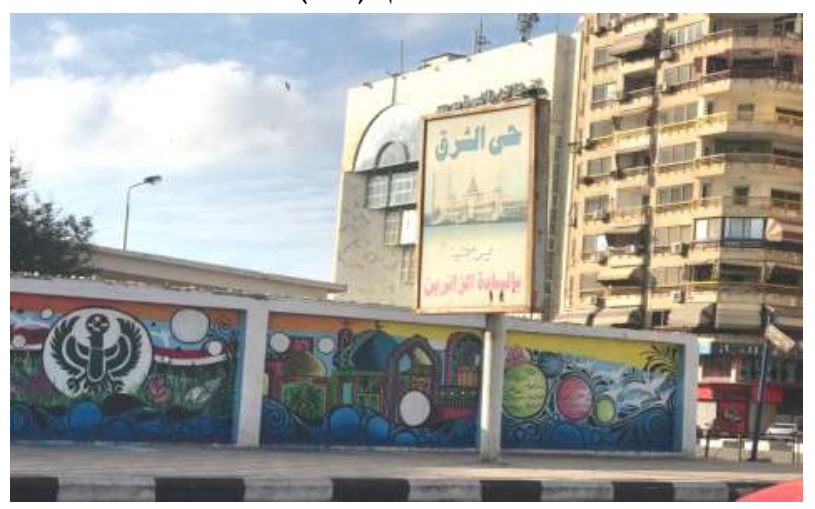

صورة رقم (ع ا)

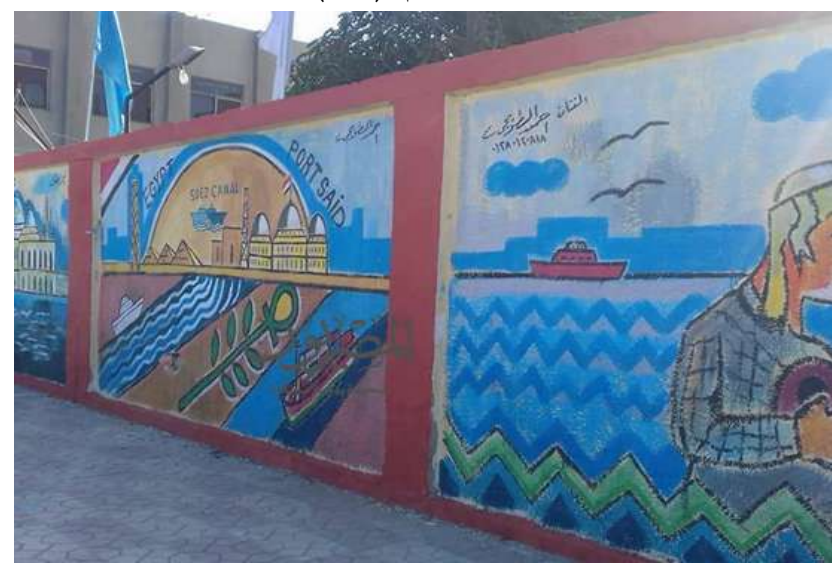

صورة رقم (10) 


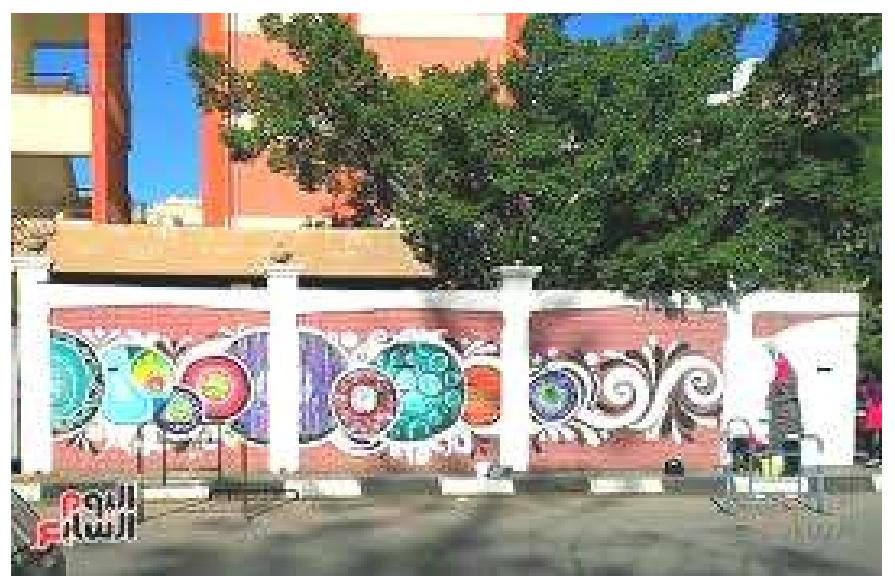

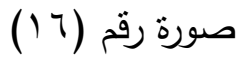

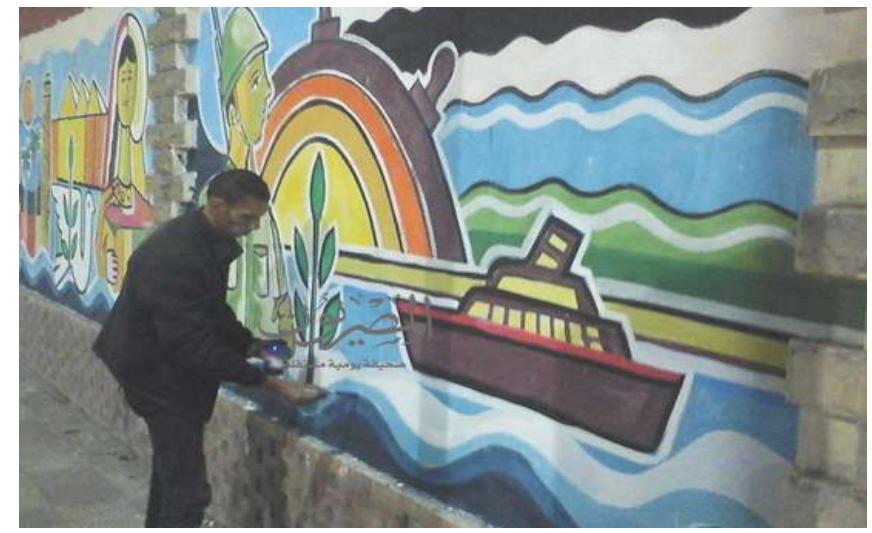

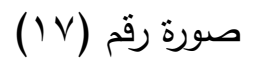

الاراسات المرتبطة : أمبات

1-المياء محمود قطب حسن فن التصوير الجداري في الوطن العربي و دورة في مواجهه

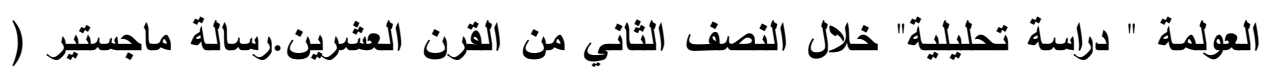
تخصص تصوير) جامعه المنيا كلية الفنون الجميلة - قسم التصوير - شعبة

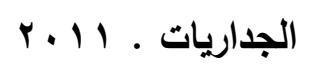

تتتاول الباحثة العولمة كظاهرة ثقافية وتأثنيرها على الثقافة بوجه عام والفن بصفة خاصة

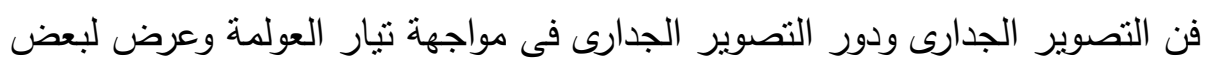
الجداريات العربية فى القرن العشرين من خلال دراسة تحليلية.

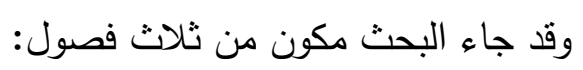
• الفصل الأول: وعنوانه (العولمة وآثارها الفنية والتقافية) وينقسم إلى فئ 
أولاً: تعريف العولمة ومفهومها، وتتتاول فيه الباحثة أهم التعريفات المتعلقة بالعولمة وتاريخها.

ثانياً: العوامل المؤثرة فى نوع ومجال العولمة، حيث أنقسمت العولمة إلى: عولمة اقتصادية،

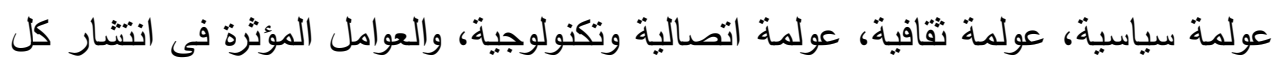

$$
\text { نوع على حده. }
$$

ثالثاً: إيجابيات وسلبيات العولمة الفنية فى عرض لطرق الاستفادة إيجابياً من العولمة وكيفية الابتعاد عن سلبياتها فى مجال الفن.

رابعاً: العولمة وتأثيرها الثقافى الفنى على الوطن العنى العربى، حيث تتاولت الباحثة " مدى تأثنير

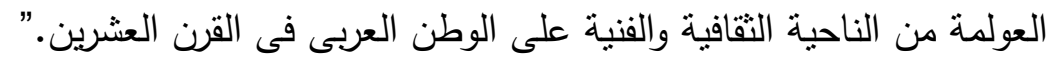
الفصل الثانى: وعنوانه (فن التصوير الجدارى فى الوطن العربى خلال القرن العشرين)

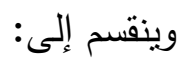

أولاً: الموضوعات والأساليب الفنية فى التصوير الجدارى فى مصر والوطن العربى (قديماً وحديثاً) وفيه نتتاول الباحثة " التصوير الجدارى من حيث التعريف والمفهوم وتاريخ التصوير الجدارى عبر العصور البدائية والمصرية القديمة والفنون الإسلامية وأساليب

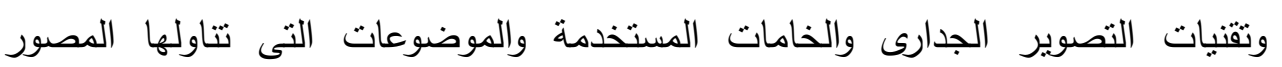

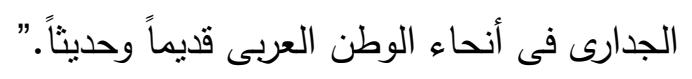

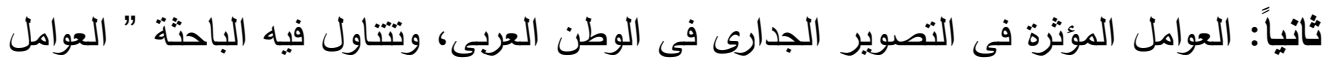

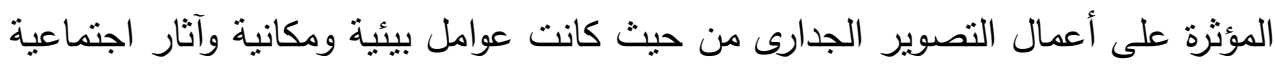

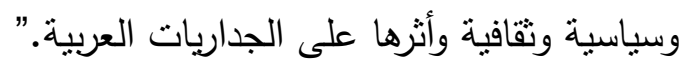

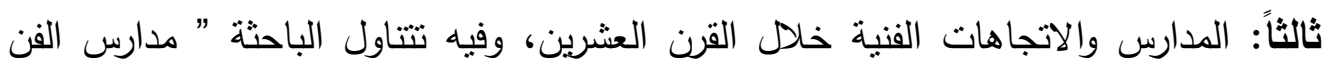

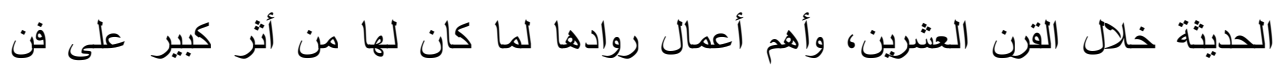

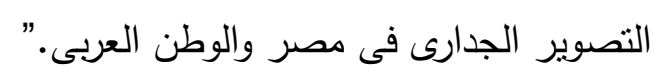

الفصل الثالث: وعنوانه (التصوير الجدارى ودوره فى مواجهة العولمة)، وينقسم إلى:

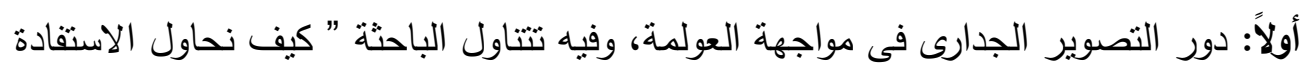

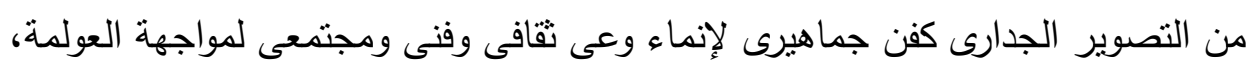

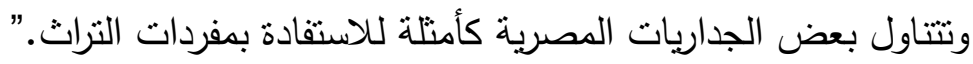
ثانياً: العولمة والحداثة، وتتتاول فيه الباحثة ” علاقة العولمة بالحداثة والعالمية، وتتناول

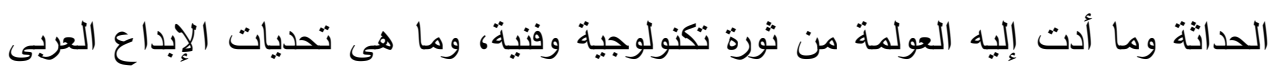

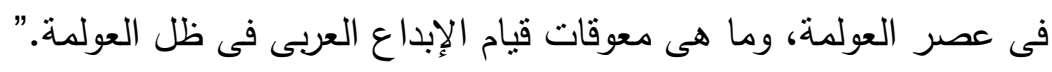


ثالثاً: دراسة تحليلية لنماذج من الأعمال الفنية الجدارية فى الوطن العبى، حيث تثتاول

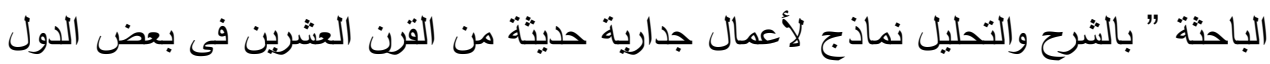

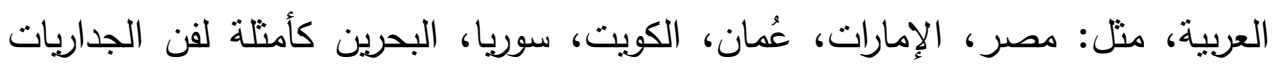

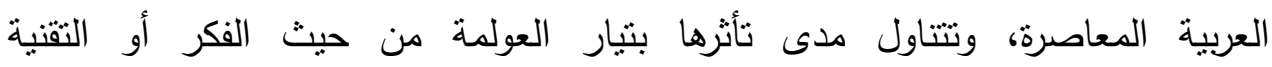
والخامة المستخدمة ".

ويستفيد الباحث من الدراسة من انة يجب ان تتناسب الموضوعات الفنبة مع العصر ويضف انة يجب ان تتفق مع معاير الخطة الاستراتيجية القومية. r-هانم صبرة حفظي عبد اللطيف ـ التصوير الجداري و دورة في أيجاد معالجات تثكيلية لمدينة المنيا الجديدة ـ رسالة ماجستير ( تخصص تصوير) جامعه المنيا كلية القنون

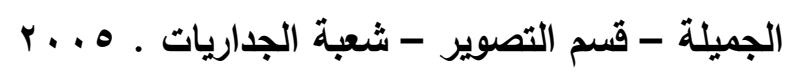

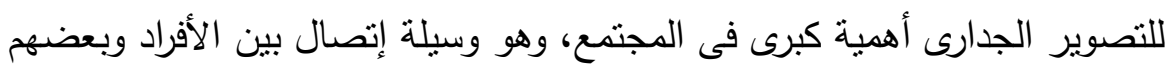
البعض إلى جانب إنه وسيلة إتصال عالمية أيضاً. وهو يرتبط إرتباطاً وثيقاً بالحضارة الإنسانية، فمنذ جداريات الكهوف ورسوماتها المختلفة التى التى تجسد عمليات القنص والصيد ومروراً بجداريات المصرى القديم وتسجيل الحياة اليومية والثعائر الدينية وغير ذلك من أمجاد وبطولات أصحاب المقابر من النبلاء والملوك والأمراء. هذا إلى جانب الفن القبطى وتسجيل تعاليم الدين الجديد على جدران الكهوف والمعابد،

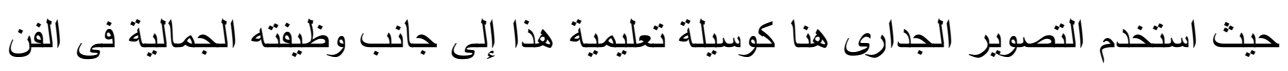

$$
\text { الإسلامى وغيره من الفنون والحضارات الأخرى. }
$$

هذا وقد كان لفن التصوير الجدارى أهمية إجتماعية وسياسية كبرى فى بعض ونس الحضارات ومنها حضارة المكسيك حيث كان هذا الفن مرآة تعكس الواقع الإجتماعى لتلك الحضارة. وقد كان للتقدم التكنولوجى أثره العميق على فن التصوير الجدارى حيث تعددت الوسائل

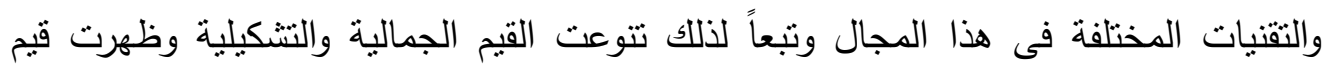
أخرى داخل العمل الفنى الواحد منها القيم الملمسية. وقد أثرى ذلك المعالجات التشكيلية فى مجال التصوير الجدارى خاصةً بعد ظهور التكنولوجيا الحديثة كما ذكرنا من قبل واستحداث خامات كيماوية جديدة فى هذا المجال تتفق لهن وإستخدامات التصوير الجدارى فى الوقت الحديث. 
وقد جاءت الدراسة فى هذا البحث مكونه من ثلاثة أبواب على النحو التالى :

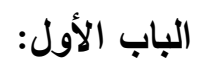

القيم الجمالية وعلاقتها بالدور الوظيفى لفن العمارة

$$
\text { وينقسم هذا الباب إلى فصلين: }
$$

الفصل الأول: مفهوم التصوير الجدارى وعلاقته بفن العمارة وفيه قامت الباحثة بشرح مفهوم التصوير من خلال زوايات متعددة: أولا /مفهوم التصوير الجدارى من الناحية اللغوية. ثانيا/ من الناحية التكنولوجية الكيميائية .. وفيه نوضح الباحثة علاقة التصوير بالعمارة من

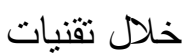
الأفرسكو والفسيفساء.

ثالثاً/التصوير الجدارى من الناحية الإجتماعية والوظيفية .. وفيه تقوم الباحثة بشرح علاقة التصوير الجدارى بالمجتمع والأفراد فيه والرسالة التى يحققها فى هذا المجتمع. وتتنقل الباحثة فى جزء آخر من هذا الفصل إلى العلاقة بين المصور الجدارى والبيئة المحيطة وما تحتويه من مقومات تؤثر فى إختيار المصور الجدارى للخامات المناسبة لتتفيذ عمله الفنى.

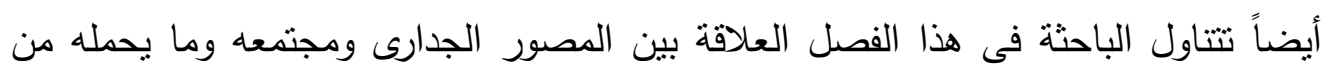
عادات وتقاليد متوارثة وقيم ومنل عليا. وينتهى هذا الفصل بتوضيح مدى علاقة وإرتباط التصوير الجدارى بالعمارة فى بعض العضارات مثل العمارة المصرية القديمة والعمارة القبطية والعمارة الإسلامية.

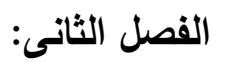

المعالجات التتكيلية فى التصوير الجدارى المصرى المعاصر وفى هذا الفصل تتطرق الباحثة للمعالجات التتكيلية فى التصوير الجدارى المصرى المعاصر عند بعض الفنانين، حيث تختلف المعالجات من فنان لآخر تبعاً لإختلاف الخامة والمكان بأبعاده الوظيفية

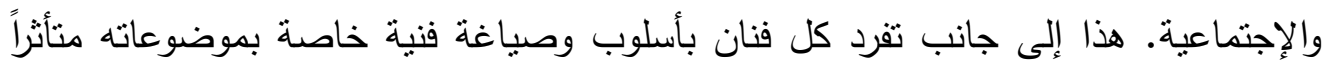
فيها بنشأته وخبراته ومستواه التعليمى والثقافى،وقد تتوعت هذه المعالجات بين الأساليب القديمة والتقليدية ولكن بموضوعات حديثة تنتاسب والمكان، وإن كان بعضها مستلهماً من التراث المصرى القديم. 
والبعض الآخر بأساليب حديثة ومعاصرة للتطور التكنولوجى وما صاحبة من إدخال

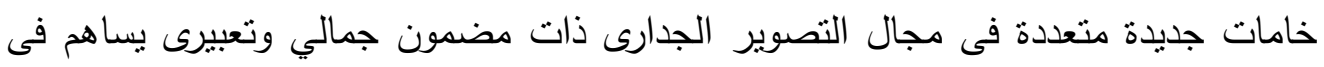
إنجاح العمل الفنى، خاصةً وأن كثير من الفنانين يعتمدون على الخامة كمثير فنى. الباب الثانى: ماهية التصوير الجدارى المقترح بالمنيا الجديدة وينقسم هذا الباب إلى ثلاثة فصول:

الفصل الأول: الأبعاد الوظيفية المختلفة للأبنية وعلاقتها بالتصميم تتاولت الباحثة فى هذا الفصل الأبعاد الوظيفية للأبنية وعمائرها المختلفة وعلاقتها بالتصميم فى بعض العصور والفنون، وقد تطرقت قبل هذه النقطة إلى قضية الثكل والمضمون فى العمل الفنى وما يحتويه من قيم جمالية منباينة، عادة ما تكون أحد أسباب

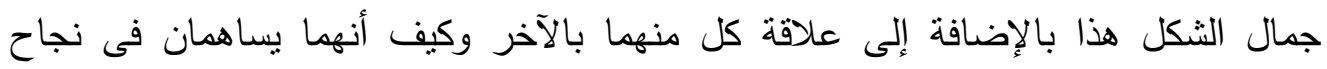
العمل الفنى أو فثله. وقد تتاولت الباحثة أيضاً كيفية تعبير الفنان عن المضمون من خلال المادة. وقد تطرقت الباحثة بعد ذللك إلى: ـ الأبعاد الوظيفية للأبنية وعلاقتها بالتصميم فى الفنون البدائية .. وتتتاول الباحثة هنا

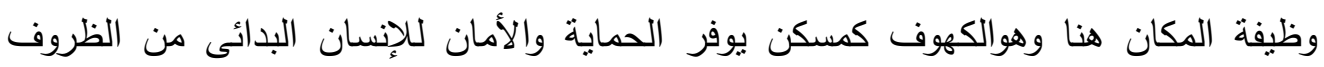

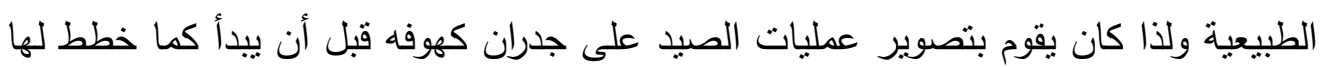
مسبقاً، هذا إلى جانب رسوم الحرب التى تؤدى إلى زيادة شعور القبيلة بالقوة. الأبعاد الوظيفية وعلاقتها بالتصميم فى الفن المصرى القديم.

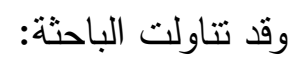
• إيمان المصرى القديم بعقيدته وأثر ذلك فى إثراء البعد الوظيفى. تجسيد عقيدته من خلال تصويرها على جدران العمائر المختلفة.

تصوير تفاصيل الحياة اليومية والثعائر والطقوس الدينية والمشاهد الجنائزية على جدران مقابرة.

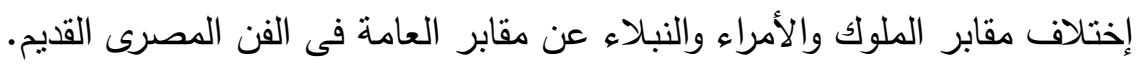
الأبعاد الوظيفية وعلاقتها بالتصميم فى الفن الرومانى .. وتتمل: تتوع العمارة الرومانية بإختالاف وظائفها. تتوع موضوعات التصوير التى استمدت موضوعاتها من الأساطير والمواقع الحربية والصور الثخصية. 
وقد أهتم الفنان الرومانى بتزيين صوره بإطارات زخرفية، وقد أهتم الفنان أيضاً بنسجيل

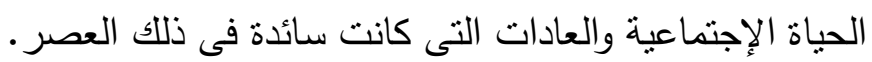

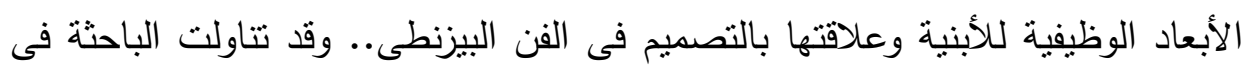

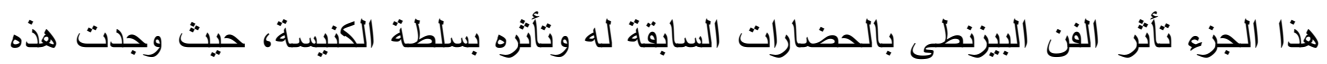
الصور فى الكنائس ومثال ذلك كنيسة القديس فيتالي. وقد عكست تلك الصور الجدارية الوحدة بين السلطة الروحية للكنيسة وسلطة الدولة المادية فى ذلك العصر .

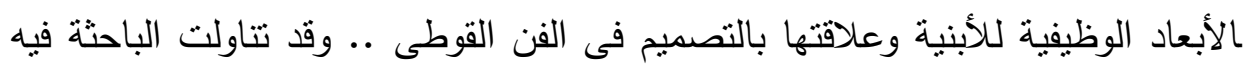

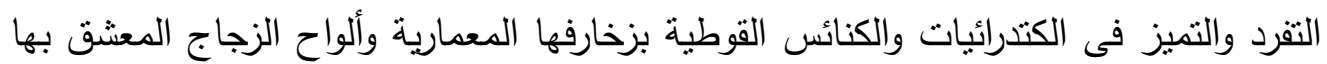
الذى انتشر فى ذلك الوقت نظراً للنطور المعمارى الذى كان من أحد ملامحه زيادة الفتحات

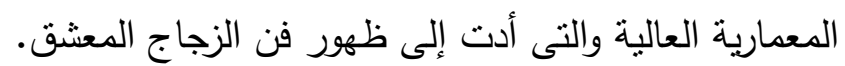

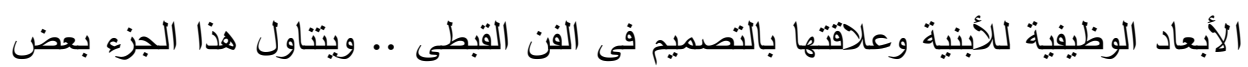
سمات الفن القبطى وكيفية وجوده كنتيجة حتمية لرغبة الثعب فى التعبير عن ذاته فى ظل قيم لإني روحية تختلف كل الإختلاف عن العقائد الوثثبة. هذا بالإضافة إلى المراحل التى مر بها الفن لفن القبطى والموضوعات التى عالجها. الأبعاد الوظيفية للأبنية وعلاقتها بالتصميم فى الفن الإسلامى .. ويتتاول هذا الجزء مدى الجى تفرد العمارة الإسلامية بعناصرها المختلفة إلى جانب نتوع أثنكال العمائر تبعاً لأبعادها الوظيفية التى انعكست على فنون التصوير إلى جانب ذلك سمات وخصائص التصوير الإسلامى. وقد شمل هذا الجزء عرض لبعض الأماكن الإسلامية وما عليها من تصاوير جدارية. وقد تطرق هذا الجزء إلى التقنيات المختلفة التى ظهرت فئى الفن الإنى الإسلامى ومنها

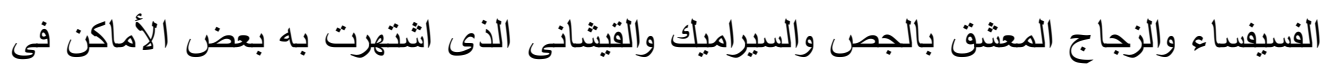
ذلك العصر . الأبعاد الوظيفية للأبنية وعلاقتها بالتصميم فى فن عصر النهضة... ويشمل هذا الجزء نبذة عن بداية عصر النهضة. كما يحتوى على الإهتمام بدراسة المصور للمنظور وأبعاده الخطية والنسب والتشريح وقد كان الفن فى تلك الفترة يخضع لنفوذ رجال الإنى الدين، وكان الفنان

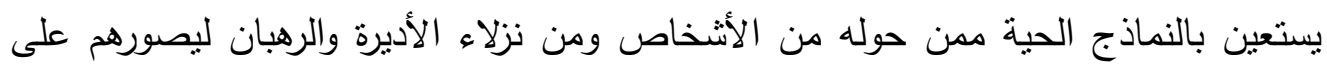

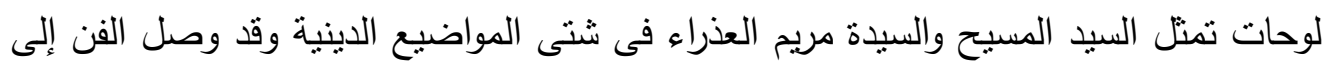
مرحلة الإزدهار فى ذلك العصر خلال القرن السادس عشر على يد مجموعة من الفنانين أمثال ليوناردو دافنشى وميكلأنجلو ورافائيل. 
الأبعاد الوظيفية للأبنية وعلاقتها بالتصميم فى الفن الحديث والمعاصر .. وتوضح الباحثة فى هذا الجزء علاقة الثكل بالمضمون والتصوير بالعمارة وإختلاف المبانى المعمارية

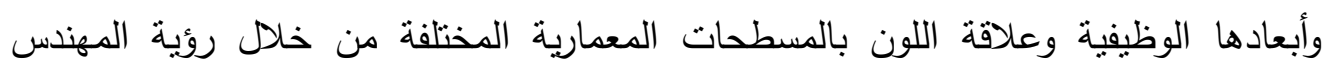
والمصدم معاً.

وتقوم الباحثة فى هذا الجزء بتحليل العلاقة بين المهند المعمارى والفنان المصور من

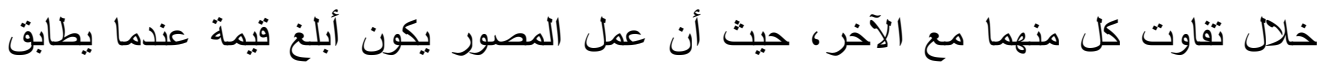

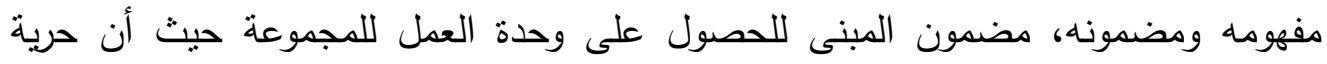
الإبتكار مكفولة له.

وفى هذا الجزء تعرض الباحثة مجموعة من الفنانين المصريين وأعمالهم الجدارية التى لهى يحتوى مضدونها على مفهوم البعد الوظيفى للمبنى الذى توجد عليه أو بداخله.

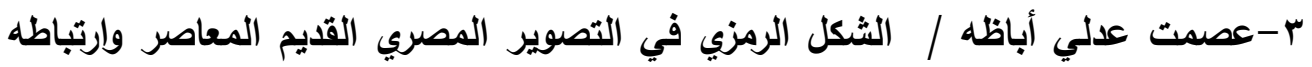
بفنون التراث المحلى، أثر ذلك على تدريس التصوير بكلية التربية الفنيةرسالة دكتوراه

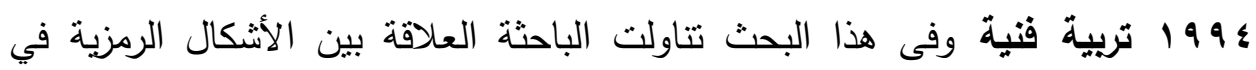

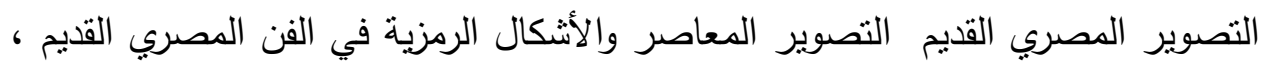
والعمليات المرتبطة بالأبدع الفني في التراث وعند الفنان المعاصر ثم تحدثت عن الرسوم المصرية القديمة وأهم الآلهة المصرية ، وعرض الأدوات والألوان المستخدمة ثم التحليل لبعض مقابر الدولة الحديثة وبعض البرديات، وأهم السمات التي تميز الفن الدصري القديه والقيم. غير أن الباحث في الدراسة الحالية يتتاول كيف يمكن الستلهام من الفن المصري القديم في التصوير الجداري. ع-جمال رفعت لمعي: أثر الرسوم المصرية القليمة على تنمية التذوق الفنى لدى الكبار رسالة دكتوراه ، تربيه فنية وفى هذا البحث تتاول الباحث أثز الرسوم المصرية على لثى لئه

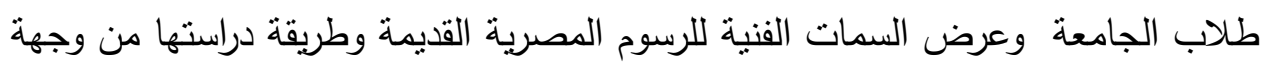

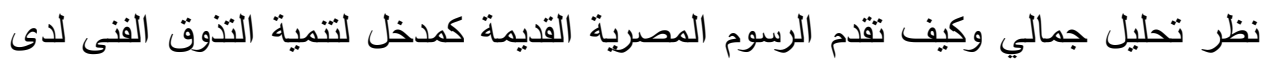
طلاب الجامعة كما وضح هذا البحث الأسباب والعوامل التي ساعدت على ظهور الأسلوب الفنى الخاص بالرسم، مرور الفنان بمراحل مختلفة للوصول إلي الأسلوب الفنى.

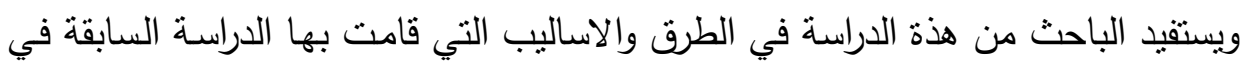
تتمية التذوق الفني لدي الكبار ولكن وجة الاختلاف في ان الدراسـة السابقة كان المتلقي هم 
طلاب الجامعة و لكن في الدراسة الحالية المتلقي الجمهور لان الدراسة تعتمد علي التصوير الجداري وتختلف الدراسة الحالية عن الدراسة السابقة انة تقوم علي موضوعات تتاسب مديتة بورسعيد وتتفق مع معاير الخطة الاستراتيجية الفومية للمدينة والي مصر عموماُ . مصطلحات البحث.

الاستراتيجية القومية : الاستراتيجية الوقومية هي مجمل الخطط البعيدة المدى لتطور

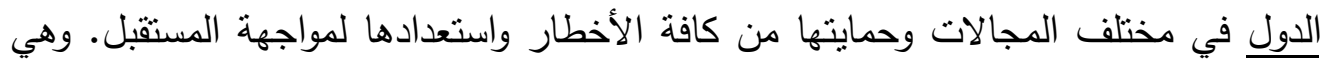

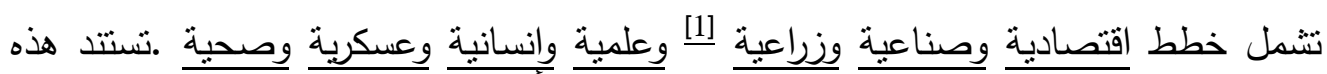

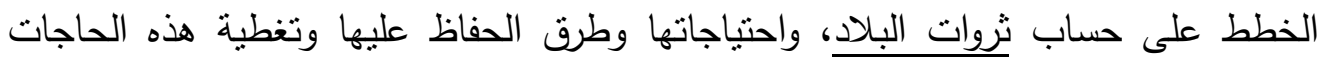

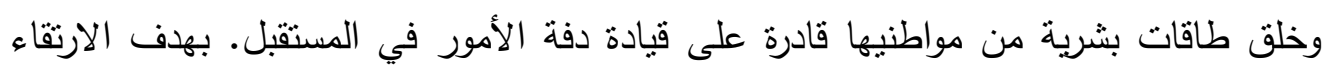
بمستوى الحياة في البلاد وتخفيف حدة الطوارئ التي قد تحدث بعمل حساب لها والتخطيط لمواجتها. بعض الدول قد تغطي •0 عاما باستراتجياتها الوطنية أو اكثر ـ وتترك الخطط

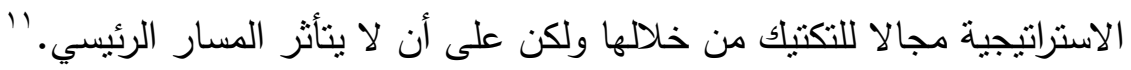
ومعني الاسترتيجيات القومية بالبحث هي نفسها السابقة ولكن علي مسار مضغر لهن المتمثل بمدينة بورسعيد ، وكيف تتفق هذة الاسترايجيات بالنواحي الايجابية بالفن . النتائج والتوصيات: انة يجب ان تكون هناك جهات مسئولة ومختصة عن التصوير الجداري وتحت اشراف اساتذة متخصصين بالفنون حتي تظهر هذة اللوحات بالمظهر الائق فنينأ

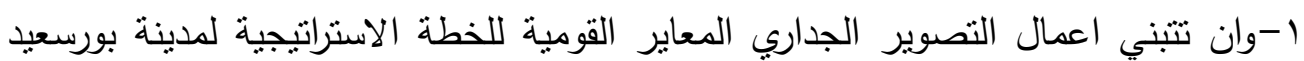

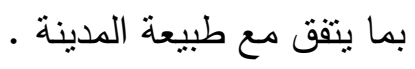


1 - ثروت عكاثه - الفن المصري القديم - الجزء الثاني - النحت والتصوير الطبعه الثانية الهيئه العامه

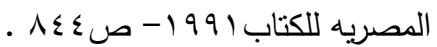

- ${ }^{3}$ http://masr-bitna.blogspot.com.eg/2014/09/blog-post.html

- $\quad{ }^{4}$ http://www.akhbarak.net/news/2018/03/05/14661127/articles/29822911/\%D8\%

AC\%D9\%84\%D8\%A7\%D8\%AF\%D9\%8A\%D8\%B3-

$\%$ D8\%AD $\%$ D8\%AF\%D8\%A7\%D8\%AF-\%D9\%84\%D9\%80-

\%D9\%83\%D9\%84\%D8\%A7\%D9\%85-\%D8\%AE\%D9\%81\%D9\%8A\%D9\%81$\% \mathrm{D} 9 \% 87 \% \mathrm{D} 8 \% \mathrm{~B} 0 \% \mathrm{D} 9 \% 87-$

\%D9\%85\%D8\%B1\%D8\%A7\%D8\%AD\%D9\%84-

$\% \mathrm{D} 8 \% \mathrm{AA} \% \mathrm{D} 8 \% \mathrm{~B} 7 \% \mathrm{D} 9 \% 88 \% \mathrm{D} 8 \% \mathrm{~B} 1-$

\%D8\%A7\%D9\%84\%D8\%A3\%D8\%B2\%D9\%8A\%D8\%A7\%D8\%A1-

$\% \mathrm{D} 9 \% 81 \% \mathrm{D} 9 \% 8 \mathrm{~A}$

- ${ }^{5}$ http://www.sharkiatoday.com/429860-2/

- ${ }^{6} \mathrm{https}: / /$ ar.wikipedia.org/wiki/\%D8\%B2\%D8\%B1\%D8\%A7\%D8\%B9\%D8\%A9

- ${ }^{7}$ https://ar.nctodo.com/ancient-egyptian-pottery-and-ceramics

8 *والفنان علاء عوض ولا سنة ا191 19 ، ويعمل مدرسا مساعدا بكلية الفنون الجميلة بالأقصر . وكان قد حصل على بكالوريوس الفنون الجميلة بالأقصر - قسم التصوير - شعبة جدارى - ع . . r. . وماجستير بعنوان (جوستاف كليمت وأثزه على التصوير الجدارى فى العصر الحديث ) كلية الفنون الجميلة - الزمالك - جامعة حلوان r ا • r.) وهوالآن باحث بمرحلة الدكتوراه بعنوان ( رؤية تشكيلية مستلهمة من جداريات الحرب والسلام

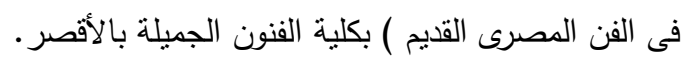

- 9 http://ar.theasian.asia/archives/32550

- 10 https://ryanalshibany.wordpress.com/category/uncategorized/

- 11

https://ar.wikipedia.org/wiki/\%D8\%A7\%D8\%B3\%D8\%AA\%D8\%B1\%D8\%A7 $\%$ D8\%AA \%D9\%8A\%D8\%AC\%D9\%8A\%D8\%A9_\%D9\%88\%D8\%B7\%D9\% $86 \% \mathrm{D} 9 \% 8 \mathrm{~A} \% \mathrm{D} 8 \% \mathrm{~A} 9$ 